\title{
Solutions for swimmer's shoulder, baseballer's elbow and runner's upper respiratory tract infection
}

\author{
Karim M Khan
}

As BJSM begins a record-breaking year (see below), I'll try to tempt you to spend more time on our site than you can really afford. Please scan the subheadings for your pet topics.

\section{Swimmer's shoulder}

This is a big problem and has traditionally been considered to have multifactorial aetiology. But Myanmar's Mya Lay Sei has partnered with global shoulder heavyweight George Murrell to discover that distance swum is a critical predictor ${ }^{1}$ (see page 105). Load, load, load - do not ignore load! This may have a big influence for swimming physios, docs and coaches. Not to mention biomechanists. And remember that BJSM's April 2010 issue, edited by Kibler, Pluim and van Cingel, focuses on shoulder pain. Just one of our 16 issues per year (in case I forget to mention that).

\section{Baseball pitcher's elbow}

Interpreting the significance of growth plate images on X-ray is a challenge for medical students, residents, fellows, and even experts. Normal variant or pathology? This paper from $\mathrm{Brazil}^{2}$ (see page 90) helps to clarify that issue. And if you are treating paediatric sports injuries remember to check back to the January 2010 issue(http://bjsm.bmj.com/content/vol44/ issue1/?etoc), which raised lively debates (http://blogs.bmj.com/bjsm/) about kids, their treatment, and their injuries.

\section{'Medical' issues - respiratory symptoms and high-level competition}

An upper respiratory tract infection can wipe out four years of training if it

Correspondence to: Dr Karim M Khan, Department of Family Practice, Faculty of Medicine, The University of British Columbia, 303-2647 Willow St, Vancouver, British Columbia V5Z 1M9, Canada; karim.khan@familymed.ubc.ca strikes at a critical time. And infections are most common immediately before or after high-level competition. Difflam throat spray was tested as a way to prevent upper respiratory symptoms in association with a half-marathon race $^{3}$ (see page 127).

\section{Economics in sports and exercise medicine - here to stay!}

A Canadian systematic review (on which I am an author) has already been tabled in the New Zealand parliament as sensible folks tried to help Prime Minister John Key make a quality decision. The issue was to keep funding exercise classes, which save the nation money by reducing fall-related injuries in seniors ${ }^{4}$ (see page 80 ). The days of anyone arguing that that health economics is not sports medicine are patently over. Ask the Australasian College of Sports Physicians as they negotiate with the Rudd government to fund their specialty - a specialty that has the potential to limit the economic burden of physical inactivity. Physical inactivity costs the US over $\$ 1$ trillion annually; clearly exercise is medicine - and good value at that.

\section{Conference preview - book now for AMSSM in Cancun!}

Sign up to be a part of AMSSM's excellent conference in Cancun, in Mexico's Mayan Riviera. Your family will love you for that! At this friendly and value-packed conference you will hear the latest from Tim Hewett ${ }^{5}$, Bert Mandelbaum, Kevin Guskiewicz (concussion) and many more; even more importantly, the AMSSM conference is renowned for letting you get up close and personal to ask your specific questions - one-on-one time with these folks and others. And that's really something you can't get any other way. Book now for 17-21 April 2010 and remember that AMSSM shows its welcome for international guests by sharing its member conference registration rate with all nonNorth Americans.

\section{Podcasts, blogs and BMJ Learning}

Read more on the blog. Listen to the podcasts (concussion, ACL, and more coming). Web access means you can even do CME online. Check out http://learning. bmj.com/; to launch the series you'll find an online, interactive ankle sprain case contributed by pre-eminent ankle expert Evert Verhagen. (You have to register with BMJ Learning but it's free and there'll be more to follow so it is definitely worth it).

\section{6 issues per year, $>1000$ submissions,} $\mathbf{1 . 5}$ million page downloads!

$B J S M$ helps you serve patients by providing valuable information, tips and tools. You receive 16 issues a year (thanks to our partnership with the IOC for four special 'Injury Prevention and Health Protection' issues). We average over 100,000 page downloads per month. Last year, we passed the 1,000 submissions mark on 2 December. All of that is good news for readers.

Competing interests: KMK is a coauthor on the paper by Davis et al. ${ }^{4}$. This paper was brought forward to print publication (as many papers are for various reasons). In this case, the reason was the paper's prominence in a national parliamentary debate.

Br J Sports Med 2010;44:79-79

doi:10.1136/bjsm.2010.071399

\section{REFERENCES}

1. Sein ML, Walton J, Linklater J, et al. Shoulder pain in elite swimmers: primarily due to swim-volumeinduced supraspinatus tendinopathy. Br J Sports Med 2010;44:105-13

2. Murachovsky J, Ikemoto RY, Nascimento LGP, et al. Does the presence of proximal humerus growth plate changes in young baseball pitchers happen only in symptomatic athletes? A $x$ ray evaluation of 21 young baseball pitchers. Br J Sports Med 2010;44:90-4.

3. Cox AJ, Gleeson M, Pyne DB, et al. Respiratory symptoms and inflammatory responses to a Difflam throat spray intervention in half-marathon runners: a randomised controlled trial. $\mathrm{Br} J$ Sports Med 2010;44:127-133

4. Davis JC, Robertson MC, Ashe MC, et al. Does a home-based strength and balance programme in people aged $\geq 80$ years provide the best value for money to prevent falls? A systematic review of economic analyses of falls prevention interventions. Br J Sports Med 2010;44:80-9.

5. Quatman CE, Hewett TE: The anterior cruciate ligament injury controversy: is "valgus collapse" a sex-specific mechanism? Br J Sports Med 2009;43:328-35. 